\title{
Disrupted sleep patterns and daily functioning in patients with chronic pain
}

\author{
Lance M McCracken $\mathrm{PhD}^{1}$, Grant L Iverson $\mathrm{PhD}^{2}$
}

LM McCracken, GL Iverson. Disrupted sleep patterns and daily functioning in patients with chronic pain. Pain Res Manage 2002;7(2):75-79.

OBJECTIVE: To investigate the role of disturbed sleep in the daily functioning of persons with chronic pain.

SUBJECTS AND METHODS: Participants comprised 287 patients seeking treatment for chronic pain at a university pain clinic. All patients completed the measures employed in the present study as part of a comprehensive initial evaluation.

RESULTS: Descriptive analyses showed that $88.9 \%$ of patients reported as least one problem with disturbed sleep. Correlation analyses showed that greater sleep disturbance was associated with greater pain, disability, depression and physical symptoms, and less daily uptime. Hierarchical regression analyses showed that sleep disturbance predicted disability, daily uptime and physical symptoms independent of pain or depression.

CONCLUSIONS: Sleep disruption is usually considered to be a consequence of the pain experience. However, the results of the present study reinforce the view that sleep disturbance may have a bidirectional relation with other features of chronic pain. Future studies should confirm that repairing disrupted sleep leads to an improvement in patients' daily activity and a reduction in their suffering.

Key Words: Assessment; Chronic pain; Daily activity; Sleep

\section{Troubles du sommeil et de fonctionnement dans la vie de tous les jours chez les patients souffrant de douleurs chroniques}

OBJECTIF : Étudier le rôle des troubles du sommeil dans le fonctionnement quotidien des personnes souffrant de douleurs chroniques.

SUJETS ET MÉTHODE : Deux cent quatre-vingt-sept patients fréquentant un centre universitaire de traitement de la douleur chronique ont participé à l'étude. Tous les sujets ont rempli les mesures utilisées dans la présente étude pour leur première évaluation globale.

RÉSULTATS : Des analyses descriptives ont montré que 88,9\% des patients ont fait état d'au moins un trouble du sommeil. Selon des analyses de corrélation, plus les troubles du sommeil étaient importants, plus intenses étaient la douleur, l'incapacité, la dépression et les symptômes physiques et moindre était le temps de fonctionnement quotidien. Des analyses avec régression hiérarchique ont révélé que les troubles du sommeil se comportaient comme des prédicteurs d'incapacité, de diminution du temps de fonctionnement quotidien et de symptômes physiques, indépendants de la douleur et de la dépression.

CONCLUSION : On considère généralement que les troubles du sommeil sont une conséquence de la douleur. Toutefois, les résultats de la présente étude renforcent le point de vue selon lequel les troubles du sommeil peuvent avoir un lien bidirectionnel avec d'autres éléments de la douleur chronique. Des études à venir devraient confirmer que le traitement des troubles du sommeil permet d'améliorer le fonctionnement des patients dans leur vie de tous les jours et d'atténue leur souffrance.

\footnotetext{
${ }^{1}$ Pain Management Unit, Royal National Hospital for Rheumatic Diseases, and the University of Bath, Bath, United Kingdom; ${ }^{2}$ University of British Columbia and HeartLink Canada Inc, Vancouver, British Columbia

Correspondence: Dr Lance McCracken, Pain Management Unit, Royal National Hospital for Rheumatic Diseases, Bath BA1 1RL,

United Kingdom. Telephone +44-1225-465941, fax +44-1225-473461, e-mail Lance.McCracken@rnhrd-tr.swest.nhs.uk

Received for publication March 26, 2001. Accepted December 14, 2001
} 
$\mathrm{It}_{\mathrm{t}}$ is clear that many people who suffer from chronic pain experience significantly impaired quality of life. This impairment often includes a loss of the normal rhythm of daytime and nighttime activity. Physical and other productive daily activities are low and uneven. Sleep is irregular, and often not compartmentalized into the evening and morning hours, as in normal, healthy adults $(1,2)$. In many ways, acquired patterns of disrupted activity and sleep may perpetuate patients' suffering.

Clearly, sleep is needed for the body to continue to function normally. In clinical settings, it is common to see patients with chronic pain who feel unrestored from inadequate sleep and complain of low energy. Disturbed sleep may contribute to overall patient disability and suffering in a number of ways. First, particular disruptions of sleep physiology can produce musculoskeletal pain, fatigue, mood disturbance and other diverse symptoms $(3,4)$. Second, impaired sleep may contribute to impaired mental alertness $(5,6)$. Third, sleep disturbance may function as part of a depressive syndrome, commonly seen in patients with chronic pain (7), and may perpetuate other depressive features. Excessive rest can function as avoidance, or inadequate sleep can encourage further disengagement from activity. Either result can contribute to low mood (7). Fourth, the patients' awareness that their sleep is disturbed can be additional proof that their health is poor, which can be an added source of distress. Finally, sleeping difficulties may lead to use of additional medications that may cause unwanted side effects. Despite the prevalence of sleep problems in persons with chronic pain and the importance of sleep to patients' well-being and daily functioning, only a relatively small number of clinical studies have addressed this subject.

Haythornthwaite and colleagues (1) collected sleep diary data from 46 patients seeking treatment for chronic pain. Their results showed that these patients slept an average of $5.3 \mathrm{~h}$ per night; spent 30 to $60 \mathrm{~min}$ falling asleep; and awoke, with difficulty falling back asleep, one to two times during the course of their sleep. The number of hours slept negatively correlated with measures of pain severity, depression and anxiety. Ratings of sleep quality negatively correlated with depression and anxiety. Anxiety appeared to be a reliable predictor of several aspects of sleep, including sleep latency and number of sleep interruptions. Overall, sleep variables were associated more with measures of emotional distress than with pain severity.

A more recent study used a number of self-report inventories to study extent of sleep disturbance and predictors of this disturbance in a mixed clinic and community sample of 51 persons with chronic pain (2). Eighty-eight per cent of subjects reported some type of sleep complaint. Most reported middle $(37 \%)$ or mixed $(37 \%)$ insomnia, others reported initial $(6 \%)$ or terminal $(2 \%)$ insomnia, and the remainder $(6 \%)$ reported only nonrestorative sleep or nightmares. Sixty per cent of patients attributed their sleep problems to pain, while only $8 \%$ blamed emotional issues. Patients reported an average of $6.0 \mathrm{~h}$ of sleep per night and had an average sleep latency of $47.5 \mathrm{~min}$. Sleep quality correlated negatively with pain severity, depression, and feelings of physical and cognitive arousal, and correlated positively with general daily activity. Among these correlates, pre-sleep cognitive arousal was the strongest unique predictor of sleep quality. Despite patients' beliefs that pain caused their sleep disturbance, pain severity was a weaker predictor than the other variables examined.

These studies highlight the importance of sleep disturbance in patients with chronic pain and suggest that emotional factors have a strong role as predictors of poor quality sleep. However, we are not aware of any study that has investigated the role of sleep disturbance as a predictor of quality of daily functioning in patients seeking treatment for chronic pain. Additional data regarding relations between sleep and other aspects of daily functioning could improve our understanding of how and when sleep disturbance contributes to chronic pain, highlight the importance of treatment for sleep disturbance and show when treatments to restore sleep will yield more general improvements for patients with chronic pain.

The purpose of the present study was to examine the prevalence of complaints of sleep disruption in patients with chronic pain and the relations of these complaints with measures of disability, emotional functioning and physical symptoms. We predicted that a summary score reflecting sleep disruption would be a strong predictor of depression and a moderate to strong predictor of physical and psychosocial disability, daily uptime and physical symptoms, independent of pain and depression.

\section{Subjects}

\section{SUBJECTS AND METHODS}

Participants comprised 287 consecutive patients $(65.5 \%$ women) seeking treatment for chronic pain at a university pain clinic. The average age was 46.7 years $(\mathrm{SD}=13.8)$. They had completed an average of 13.9 years of education ( $\mathrm{SD}=2.7 ; 88.9 \%$ had completed 12 years or more). Most of the patients were white $(75.6 \%)$; the remainder were black (20.7\%), hispanic (1.7\%) and Asian (1.7\%). Most of the patients were married $(53.7 \%)$, followed by single $(22.6 \%)$, divorced (16.4\%) and widowed (7.3\%). The most common primary site of pain was the lower back $(54.7 \%)$, followed by the lower extremities (14.4\%), upper extremities (8.4\%), cervical spine $(7.4 \%)$ and other sites $(14.9 \%)$. The median duration of pain was 32.5 months (range three to 372 months). All patients completed the measures for this study as part of the routine assessment procedures during their initial evaluation at the clinic.

\footnotetext{
Measures

Subjects provided information about their personal background and pain-related variables, including a $100 \mathrm{~mm}$ visual analogue scale for average pain during the past week, an estimate of daily uptime and information about current pain medications. They also completed measures of depression, physical symptoms and disability.
} 
TABLE 1

\section{Percentage of patients endorsing each complaint of} disturbed sleep or rest

\begin{tabular}{lc}
\hline Item & $\%$ \\
\hline I sleep less at night, for example, wake up too early, & 62.1 \\
don't fall asleep for a long time, awaken frequently & \\
I sit during much of the day & 40.7 \\
I lie down more often during the day in order to rest & 33.7 \\
I spend much of the day lying down in order to rest & 23.5 \\
I sleep or nap more during the day & 16.5 \\
I am sleeping or dozing much of the time - day and night & 6.0 \\
I sit around half asleep & 4.6 \\
\hline
\end{tabular}

Beck Depression Inventory: The Beck Depression Inventory (BDI) is a 21-item self-report measure assessing cognitive and vegetative symptoms of depression over a two-week period (8). Research has indicated that scores from the BDI are reliable and valid indexes of depression (9). Studies also specifically support the validity of the BDI in patients with chronic pain (10).

Modified Somatic Perception Questionnaire: The Modified Somatic Perception Questionnaire (MSPQ) is a 22-item measure of a range of physical symptoms that are often associated with emotional distress (11), and asks about symptoms experienced during the past week. It was developed specifically for use in persons with chronic back pain to assess somatic and autonomic awareness. The MSPQ has adequate test-retest reliability. Scores from the MSPQ correlate with measures of emotional distress, and discriminate 'problem' back pain referrals from routine general practitioner referrals to an orthopedic service. The MSPQ was used in the present study as a measure of physical symptoms of distress and suffering.

Sickness Impact Profile: The Sickness Impact Profile (SIP) is a 136-item, behaviour-based checklist that assesses the effect of illness on 12 categories of daily activity (12). Subjects endorse statements that describe current problems with functioning that are related to their health. Subjects are not otherwise instructed to consider a specific time period. The SIP provides an overall impact score as well as separate composite scores for physical and psychosocial dimensions. Included in the SIP is a seven-item scale measuring problems with sleep and rest. The summary score from these items was used as a measure of sleep disruption in the present study. All scores on the SIP were calculated by using the same method - by summing the scale values of endorsed items and dividing by the sum of the scale values of all the items for the desired section. The items from the SIP sleep and rest scale were not used in the calculation of the physical or psychosocial dimension scores. Research has shown that the SIP has satisfactory internal consistency, test-retest reliability and validity in a sample of persons with heterogeneous health problems (12) and in patients with chronic pain (13).

\section{RESULTS}

Initial frequency analyses showed that $88.9 \%$ of patients reported at least one problem with sleep. The endorsement rates for each item from the SIP sleep and rest scale are presented in Table 1. The most frequent complaint was sleeping less at night $(62.1 \%)$, followed by sitting most of the day $(40.7 \%)$ and lying down more often during the day $(33.7 \%)$.

Correlation analyses were conducted to show the relations of sleep problems with demographic variables; medication use; and measures of pain, daily functioning and physical symptoms. The sleep score was not correlated with age, sex, level of education or duration of pain. It was significantly correlated with antidepressant use (dichotomously coded $)(r=0.21, \mathrm{P}<0.001)$ but not correlated with the use of opioid analgesics or sedating drugs. The intercorrelations of the sleep score with the measures of pain, depression, physical and psychosocial disability, uptime and physical symptoms are presented in Table 2 . In each case, the correlations involving the sleep score were significant and in the predicted direction. Disturbed sleep correlated with greater pain, depression, disability and physical symptoms, and less daily uptime.

TABLE 2

Intercorrelations of sleep, daily functioning and physical symptom variables

\begin{tabular}{|c|c|c|c|c|c|c|}
\hline & $\begin{array}{c}\text { Sleep } \\
\text { disturbance }\end{array}$ & $\begin{array}{l}\text { Physical } \\
\text { disability }\end{array}$ & $\begin{array}{l}\text { Psychosocial } \\
\text { disability }\end{array}$ & Pain & Uptime & Depression \\
\hline Physical disability & $0.42^{\star *}$ & & & & & \\
\hline Psychosocial disability & $0.49^{* *}$ & $0.58^{* *}$ & & & & \\
\hline Pain & $0.26^{* *}$ & $0.38^{* *}$ & $0.34^{\star *}$ & & & \\
\hline Uptime & $-0.27^{\star *}$ & $-0.45^{\star *}$ & $-0.27^{\star \star}$ & $-0.24^{\star *}$ & & \\
\hline Depression & $0.41^{* *}$ & $0.41^{* *}$ & $0.73^{* *}$ & $0.26^{* *}$ & $-0.26^{\star \star}$ & \\
\hline Physical symptoms & $0.34^{\star *}$ & $0.43^{* *}$ & $0.61^{* *}$ & $0.33^{* *}$ & $-0.19^{*}$ & $0.50^{\star *}$ \\
\hline
\end{tabular}

Sleep and rest disturbance, physical disability and psychosocial disability were assessed with the Sickness Impact Profile; pain was assessed with a $100 \mathrm{~mm}$ visual analogue scale; depression was assessed with the Beck Depression Inventory; and physical symptoms were assessed with the Modified Somatic Perception Questionnaire. ${ }^{*} P<0.01 ;{ }^{*} P<0.001$ 
TABLE 3

Results of hierarchical regression analyses examining sleep and rest disturbance as a predictor of disability and physical symptoms, independent of pain and depression

\begin{tabular}{|c|c|c|c|}
\hline Criterion & & & $\mathbf{R}^{2}$ \\
\hline Predictor & Beta & $\Delta \mathbf{R}^{2}$ & \\
\hline Physical disability & & & \\
\hline Pain & 0.26 & $0.15^{\star \star \star}$ & \\
\hline Depression & 0.23 & $0.10^{* * *}$ & \\
\hline Sleep disturbance & 0.25 & $0.053^{\star \star *}$ & $0.29^{* \star \star}$ \\
\hline Psychosocial disability & & & \\
\hline Pain & 0.12 & $0.11^{\star * *}$ & \\
\hline Depression & 0.61 & $0.44^{\star * \star}$ & \\
\hline Sleep disturbance & 0.21 & $0.040^{\star \star *}$ & $0.58^{\star * \star}$ \\
\hline Uptime & & & \\
\hline Pain & -0.16 & $0.059^{\star \star *}$ & \\
\hline Depression & -0.15 & $0.041^{\star *}$ & \\
\hline Sleep disturbance & -0.16 & $0.021^{* *}$ & $0.12^{\star \star \star}$ \\
\hline Physical symptoms & & & \\
\hline Pain & 0.19 & $0.11^{* * *}$ & \\
\hline Depression & 0.39 & $0.18^{* * *}$ & \\
\hline Sleep disturbance & 0.13 & $0.014^{*}$ & $0.31^{\star \star \star}$ \\
\hline
\end{tabular}

Disability and sleep disturbance were assessed with the Sickness Impact Profile, pain with a $100 \mathrm{~mm}$ Visual Analogue Scale, and depression with the Beck Depression Inventory. ${ }^{*} P<0.05$; ${ }^{* *} P<0.01$; ${ }^{* * *} P<0.001$

Hierarchical regression analyses were used to test whether disturbed sleep is related to daily functioning and physical symptoms, independent of depression and pain. The criterion variables in these analyses were the measures of daily functioning and physical symptoms. The $100 \mathrm{~mm}$ visual analogue scale pain score and the BDI total score were entered in two steps, and the sleep score in the third step. The results of these analyses are provided in Table 3. In each equation, the sleep score accounted for a statistically significant increment of variance in the criterion variables after variance related to pain and depression was statistically controlled. In the cases of uptime and physical symptoms, the incremental contributions of sleep disturbance were small.

\section{DISCUSSION}

In the present study, $88.9 \%$ of patients seeking treatment for chronic pain reported at least one complaint that was related to a disturbed sleep and wake cycle. Other results showed that a disturbed pattern of sleep and rest was associated with greater pain, depression, physical and psychosocial disability and physical symptoms, and less daily uptime. Also, disturbed sleep and rest predicted impaired daily functioning and physical symptoms independent of pain and depression.
Previous studies of sleep in patients with chronic pain have shown the same high rates of sleep disturbance shown by our data $(1,2)$. They also showed that emotional distress variables are moderate to strong predictors of sleep disturbance, that pain severity is a weak predictor $(1,2)$ and that disturbed sleep is associated with reports of various physical symptoms $(3,4)$. We replicated these findings. Unlike previous studies that examined predictors of sleep disturbance, we chose to conceptualize sleep disturbance as a potential predictor of impaired daily functioning and adjustment in people with chronic pain. Interestingly, our results revealed that, relative to sleep disturbance, pain played a smaller role in the prediction of daily functioning. Results of this study differ from those of previous studies in the manner in which sleep was measured. Previous studies focused on sleep during the usual sleep interval for most people - the nighttime and early morning hours. Our measure of sleep included both disrupted sleep during that interval and excessive daytime rest.

The results regarding relations between medication use and sleep deserve some further comment. It is often assumed that opioid analgesics may contribute to sleepiness during the day, and that sedating medications and antidepressants contribute to good sleep at night. Our results do not support these assumptions. However, the subjects in the present study were tertiary care referrals. They were seeking treatment because previous treatments, including medications, were ineffective or unsatisfying. Also, significant numbers of patients with chronic pain do not adhere to prescriptions (14). Thus, although patients are taking medications, they may not be taking them optimally. Our results regarding antidepressant medications may reflect cases in which symptoms of depression were being treated but not completely controlled.

This study has several limitations. All data were collected by retrospective self-report. This indirect method can yield data that are influenced by many factors separate from actual sleep and rest behaviour. Also, our measure of sleep and rest disturbance was quite brief. Although it assesses global disruption of sleep and wake patterns, other aspects of sleep and activity were clearly not included. We did not assess the number of hours slept, sleep latency, the number or length of disruptions in nighttime sleep or subjective sense of sleep restfulness.

It is clear that sleep-related behaviour and sleep physiology are complex. Sleep surveys, as used here, and diary methods, as used by Haythornthwaite et al (1), clearly help researchers and clinicians assess, understand and treat patients with chronic pain and sleep disturbance. However, these methods have limitations. Diary methods are labour intensive for patients and are sometimes hampered by compliance problems (1). Survey methods can be limited by unwanted biasing influences on retrospective reports and problems related to memory $(15,16)$. Finally, it is reasonable to assume that patients' alertness may be impaired around the time that recordings are required because they are moving in and out of sleep at the time. These concerns 
support the need for both objective and more direct methods for assessing sleep disturbance, such as automated methods and electronic diaries (16-19). Another recently developed objective assessment technique involves monitoring circadian heart rate patterns. It is a method that has been used for documenting physiological dysregulation associated with psychiatric illness (20-22). Technological innovations such as these are needed to improve the study of sleep, emotional distress and activity disturbance in patients with chronic pain.

Our data confirm the often-noted clinical impression that sleep and rest are frequently disturbed in persons with chronic pain. Others have shown that the experience of chronic pain leads to emotional distress that appears to interfere with sleep. We argued that disturbed sleep could lead to distress and impaired functioning. Our results support this view. Sleep, emotional distress, pain perception and daily activity appear to form a cycle, each contributing to the other. More research is needed to examine these complex interrelations. However, our data may help to focus efforts on sleep improvement in the overall management of chronic pain.

\section{REFERENCES}

1. Haythornthwaite JA, Hegel MT, Kerns RD. Development of a sleep diary for chronic pain patients. J Pain Symptom Manage 1991;6:65-72.

2. Smith MT, Perlis ML, Smith MS, Giles DE, Carmody TP. Sleep quality and presleep arousal in chronic pain. J Behav Med 2000;23:1-13.

3. Moldofsky H, Scarisbrick P. Induction of neurasthenic musculoskeletal pain syndrome by slective sleep stage deprivation. Psychosom Med 1976;38:35-44.

4. Lentz MJ, Landis CA, Rothermel J, Shaver JLF. Effects of selective slow wave sleep disruption on musculoskeletal pain and fatigue in middle aged women. J Rheumatol 1999;26:1586-92

5. McCracken LM, Iverson GL. Predictors of neurobehavioral complaints in patients with chronic pain. J Pain Symptom Manage. (In press)
6. Côté KA, Moldofsky H. Sleep, daytime symptoms, and cognitive performance in patients with fibromyalgia. J Rheumatol 1997;24:2014-23.

7. Banks SM, Kerns RD. Explaining high rates of depression in chronic pain: A diathesis-stress framework. Psychol Bull 1996;119:95-110.

8. Beck AT, Rush AJ, Shaw BF, Emery G. Cognitive Therapy of Depression. New York: Guilford, 1979.

9. Beck AT, Steer RA, Garbin MG. Psychometric properties of the Beck Depression Inventory: Twenty-five years of evaluation. Clin Psychol Rev 1988;8:77-100.

10. Geisser ME, Roth RS, Robinson ME. Assessing depression among persons with chronic pain using the Center of Epidemiological Studies-Depression Scale and the Beck Depression Inventory: A comparative analysis. Clin J Pain 1997;13:163-70.

11. Main CJ. The Modified Somatic Perception Questionnaire (MSPQ). J Psychosom Res 1983;27:503-14.

12. Bergner M, Bobbitt RA, Carter WB, Gilson BS. The Sickness Impact Profile: development and final revision of a health status measure. Med Care 1981;29:787-805

13. Deyo RA. Measuring the functional status of patients with low back pain. Arch Phys Med Rehabil 1988;69:1044-53.

14. Berndt S, Maier C, Schutz HW. Polymedication and medication compliance in patients with chronic non-malignant pain. Pain 1993;52:331-9.

15. Erskine A, Morley S, Pearce S. Memory for pain: A review. Pain 1990;41:255-65.

16. Smith WB, Safer MA. Effects of present pain level on recall of chronic pain and medication use. Pain 1993;55:355-61.

17. Sanders SH. Automated versus self-monitoring of 'up-time' in chronic low-back pain patients: A comparative study. Pain 1983;15:399-405.

18. Lewis B, Lewis D, Cumming G. Frequent measurement of chronic pain: an electronic diary and empirical findings. Pain 1995;60:341-7.

19. Peters ML, Sorbi MJ, Kruise DA, Kerssens JJ, Verhaak PFM, Bensing JM. Electronic diary assessment of pain, disability and psychological adaptation in patients differing in duration of pain. Pain 2000;84:181-92.

20. Gaetz M, Rzempoluck EJ, Iverson GL. Approximate entropy as an index of circadian dysregulation in depression. Ann Behav Med. (Abst) (In press)

21. Iverson GL. Low activity level is associated with psychological distress and depression in primary care patients. Ann Behav Med. (Abst) (In press)

22. Stampfer HG. The relationship between psychiatric illness and the circadian pattern of heart rate. Aust N Z J Psychiatry 1998;32:298-309. 


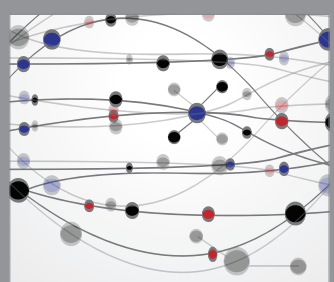

The Scientific World Journal
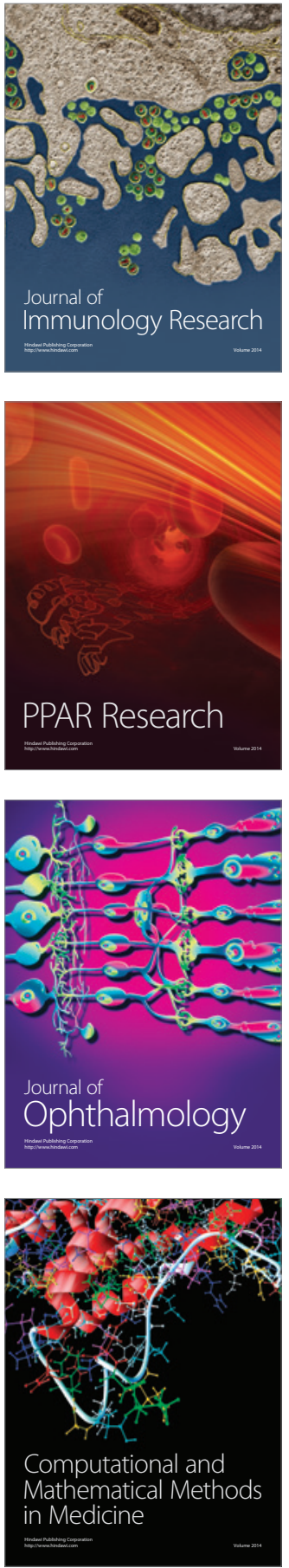

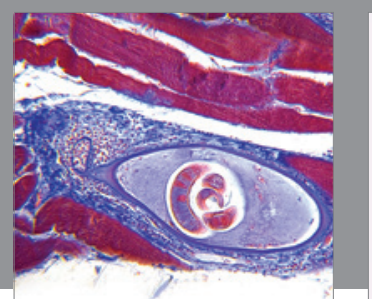

Gastroenterology Research and Practice

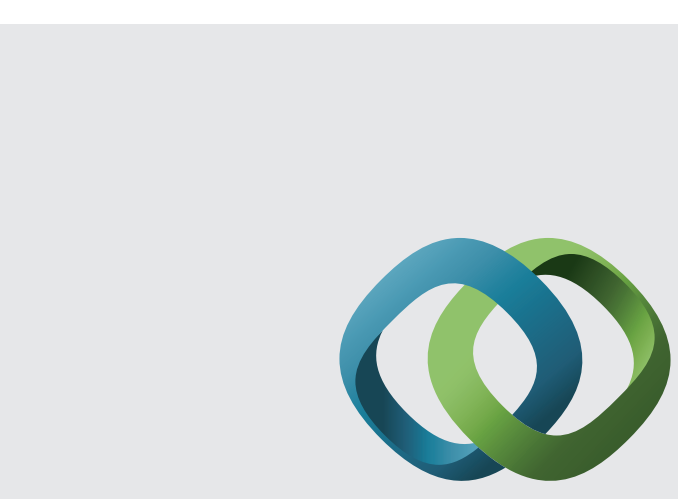

\section{Hindawi}

Submit your manuscripts at

http://www.hindawi.com
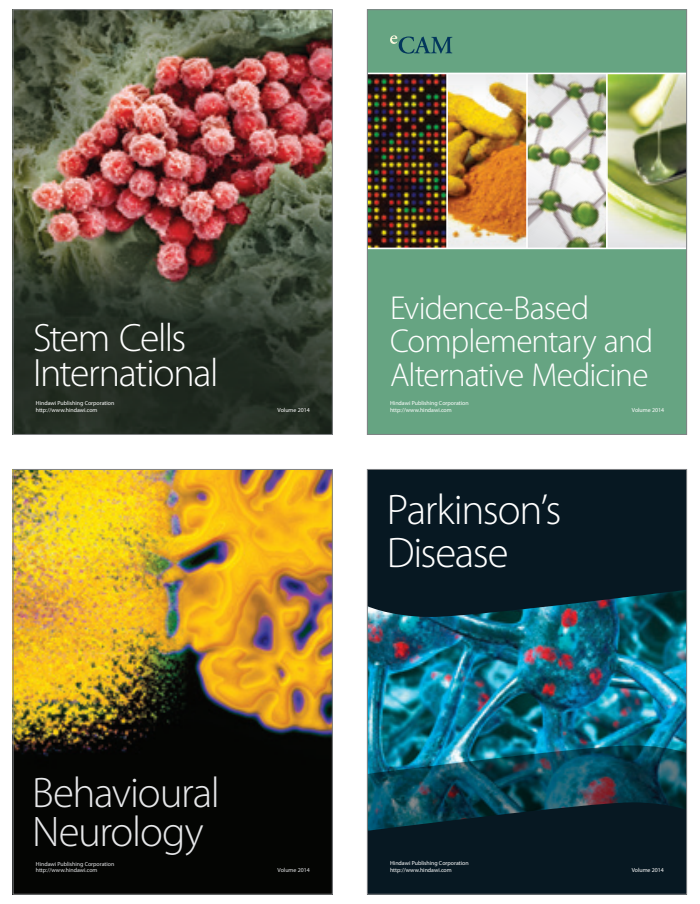
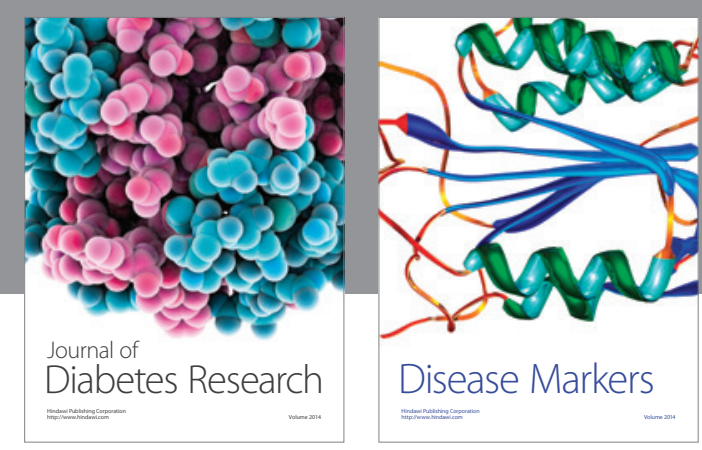

Disease Markers
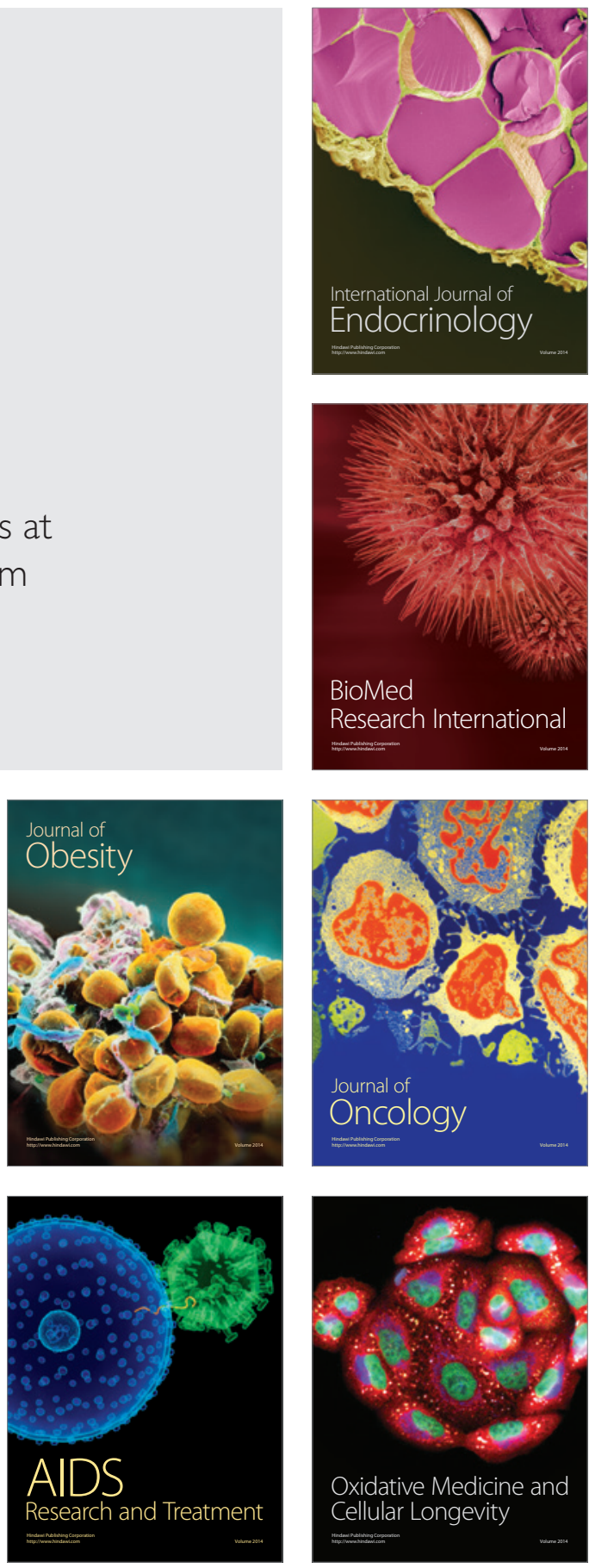